\title{
Entomopathogenic Fungi as Endophyte: An Emerging Tool for Biological Pest Control
}

\author{
Chandra Kanta Dash ${ }^{1 *} \quad$ Bamisope Steve Bamisile ${ }^{2,3} \quad$ Mohon Nondi $^{1} \quad$ Sangeeta Mitra ${ }^{4}$ \\ 1.Department of Entomology, Sylhet Agricultural University, Sylhet 3100, Bangladesh \\ 2.Plant Protection College, Fujian Agriculture and Forestry University, Fuzhou 350002, China \\ 3. State Key Laboratory of Ecological Pest Control for Fujian and Taiwan Crops, College of Plant \\ Protection, Fujian Agriculture and Forestry University, Fuzhou 350002, China \\ 4. Department of Agricultural Extension, Khamarbari, Dhaka 1200, Bangladesh \\ *E-mail of the corresponding author: dashck.entom@sau.ac.bd
}

\begin{abstract}
Biological control using fungal entomopathogen is an effective and sustainable alternative to chemical control of insect pests. However, despite enormous potential, they have not been fully utilized due to their susceptibility to unfavorable abiotic factors such as ultraviolet (UV) light and low humidity. An increasing number of studies in the last decade demonstrates that entomopathogenic fungi have wider ecology than previously thought. They have been found to colonize various plant naturally as endophyte as well as they have been successfully established in plants with various inoculation methods. In planta presence of these fungi can overcome the impediments arise from inundative application of fungal suspension as they have been found not only protect the host plant from pest and disease but also act as a plant growth promoter. In this review, we discussed the multiple benefits provided by fungal entomopathogens following their association with the host plant as an endophyte and highlights the prospects of incorporating fungal endophytes as an integral part of pest management programs towards sustainable crop production.
\end{abstract}

Keywords: Fungal endophyte, Plant colonization, Beauveria, Metarhizium, Lecanicillium

DOI: $10.7176 / \mathrm{JBAH} / 10-16-04$

Publication date:August $31^{\text {st }} 2020$

\section{Introduction}

Insect pests cause $18-26 \%$ crop loss worldwide, with a value of more than $\$ 470$ billion and the major part (13$16 \%$ ) occurs in the field (Culliney 2014). Agrochemicals have been the foremost choice to protect crops from pests for several decades. They have been responsible for increasing the quantity and quality of crops worldwide (Skinner et al. 2014). However, their extensive use has resulted in several unwanted consequences, such as the development of resistance in insect pests, secondary pest outbreak or resurgence of pests, residue in crop commodities and disruption of natural enemy population reducing the overall natural control of pests in agroecosystems (Skinner et al. 2014). As a consequence, concern about environmental impacts and human hazards from agrochemicals, have provided force scientists to develop safe and eco-friendly pest management approach alternatives to chemical pesticides.

Biological control is a viable and sustainable pest management technique that relies on using a living organism to manage insect pests which includes predator, parasitoid and microorganism such as virus, bacteria and fungus (van Lenteren et al. 2018). Among the microorganism, fungi, especially entomopathogenic fungi (EPF) has been used as an inundative approach for more than 100 years (Lacey et al. 2015). Over 700 different species of fungi from at least 90 genera are known to be pathogenic to insect pests (Khachatourians \& Qazi 2008). However, only a few of them are well-recognized as insect pathogens including Metarhizium, Beauveria, Lecanicillium, Isaria, and Hirsutella etc. More than 170 entomopathogenic fungal strains are now commercially available as mycopesticides, especially Beauveria spp. and Metarhizium spp. (Clavicipitaceae) (de Faria and Wraight, 2007). Despite of its potential, EPF are mostly underutilized because they are generally applied as inundative approach which expose them to various biotic and abiotic factors. Temperature, humidity and solar radiation are abiotic factors affecting persistence and efficacy of entomopathogenic fungi (Jaronski 2010).

An increasing number of studies in the last decade demonstrate that entomopathogenic fungi, besides insect pathogen, they have wider ecology than previously thought (Vega et al. 2009; Barelli et al. 2016). They have been reported to play an additional role in nature, including endophytism (Vega et al. 2009), rhizosphere colonizer (Hu \& St. Leger 2002; St. Leger 2008; Pava-Ripoll et al. 2011), plant disease antagonists (Ownley et al. 2004; Kim et al. 2008; Ownley et al. 2010; Jaber \& Ownley 2018) and plant growth promoter (Kabaluk \& Ericsson 2007; García et al. 2011; Sasan \& Bidochka 2012; Liao et al. 2014; Lopez \& Sword 2015; Jaber \& Enkerli 2017). Various EPF have been reported to colonize an increasing number of plants naturally, including many agriculturally important crop such as coffee, maize, cotton etc. (Jones 1994; Arnold \& Lewis 2005; Vega et al. 2008; Reay et al. 2010; Khan et al. 2012; Lefort et al. 2016) as well as their artificial inoculation and re-isolation have been successful in several important crops with various inoculation methods (Vega et al. 2009; Bamisile et al. 2018; Vega 2018) such 
as banana, tomato, cotton, rice, sugarcane and many others (see table 1) (Bamisile et al. 2018). In this review, we provide a summary of multiple benefits provided by EPF following their endophytic association in plants and highlight the prospects of including fungal endophytes as biocontrol agents in integrated pest management program.

\section{What is an endophyte?}

The term "endophyte" was introduced by de Bary (1866), to define any organism found within living plant tissues. Carroll (1988) excluded pathogenic fungi and mycorrhizal fungi and redefined endophyte as "organism that causes asymptomatic infections within plant tissues." Since then, several definitions have been proposed for endophyte (see Box 1. in Hyde and Soytong, 2008). However, we use the amended definition proposed by Le Cocq et al. (2017) that 'Endophytes are microbes which occur within plant tissue for at least part of their life cycle without causing disease under any known circumstances'. Now a days, endophyte research mainly focuses on endophytic fungi that live within plants for at least part of their life cycle without any visible symptoms (Hyde and Soytong 2008; Bacon and White 2016).

\section{Endophytic insect pathogenic fungi as plant growth promoters}

A growing number of studies have demonstrated the ability of EPF to promote plant growth when colonized artificially with various inoculation methods (Kabaluk \& Ericsson 2007; García et al. 2011; Sasan \& Bidochka 2012; Liao et al. 2014; Lopez \& Sword 2015; Jaber \& Enkerli 2016; Jaber \& Enkerli 2017; Dash et al. 2018; Bamisile et al. 2020). In a field study, Kabaluk and Ericsson (2007) found an increased yield of corn when seeds were treated with Metarhizium brunneum. Similarly, Lopez and Sword (2015) observed improvements in growth and biomass of cotton when colonized by Beauveria bassiana and Purpureocillium lilacinum. Significantly greater number of lateral roots and root hair formations were recorded from plants colonized by Metarhizium compared to untreated counterparts (Sasan \& Bidochka 2012). In another study, increased foliar biomass and leaf collar formation were reported in corn seeds when colonized with different Metarhizium strains (Liao et al. 2014). In addition, significantly greater plant height, shoot and root dry weight, root length was recorded from tomato plants colonized by Metarhizium (Elena et al. 2011).

Improvement in the stand counts and yield was recorded in wheat when plants were treated with Metarhizium roberstii, M. brunneum, and B. bassiana (Reddy et al. 2014). In another study, foliar treatment of faba bean (Vicia faba) plant with Beauveria brongniartii, B. bassiana, and M. brunneum improved the plant height, fresh shoot and root weight (Jaber \& Enkerli 2017). In a recent study, Liao et al. (2017) found that M. robertsii produces the plant growth regulator indole-3acetic acid (IAA; an auxin). This is the first report of plant growth regulator production by any EPF. Other Metarhizium and Beauveria strains were also found to produce IAA (Liao et al. 2017). In a recent study, Dash et al. (2018) found that besides B. bassiana, I. fumosorosea and L. lecanii also increased the plant height, shoot and root weight of common bean when the seed was inoculated with fungal suspension.

The mechanism of plant growth enhancement by endophytic entomopathogenic fungi is not fully elucidated yet; however, several hypotheses have been proposed. It has been found that EPF produces siderophores and organic acids, which can change the bioavailability of several nutrients (Jirakkakul et al. 2014). Furthermore, studies on endophytic fungus-plant interactions demonstrated that the positive plant growth effects could be due to the fixation of nutrients, bioactive metabolite production or up-regulation of plant growth hormone such as auxin, ethylene etc. (Berg 2009; Behie et al. 2012; Behie et al. 2017).

\section{Endophytic insect pathogenic fungi as plant disease antagonists}

There is now a plethora of evidence that some endophytic entomopathogenic fungi, particularly Beauveria bassiana and Lecanicillium lecanii (formerly Verticillium lecanii) may also exhibit antagonistic activity against plant pathogens besides their well-known biological control potential (Ownley et al. 2004; Ownley et al. 2008; Vega et al. 2009; Ownley et al. 2010; Jaber \& Ownley 2018; Vega 2018).

Antagonistic activities of $B$. bassiana on plant pathogens have been reported in many studies (Kim et al. 2008; El-Deeb et al. 2012; Sasan \& Bidochka 2013; Jaber \& Salem 2014; Jaber 2015; Barra-Bucarei et al. 2020; Canassa et al. 2020). For example, B. bassiana strain 11-98, when applied as a seed treatment, was found to suppress damping-off disease caused by Rhizoctonia solani and Pythium myriotylum in tomato (Ownley et al. 2004) and cotton seedlings (Ownley et al. 2008). Using several strains of B. bassiana, Jaber and Salem (2014), were able to reduce the incidence of Zucchini yellow mosaic virus (ZYMV; genus Potyvirus, family Potyviridae) in squash. Similarly, using Beauveria bassiana strain 11-98, pre-treatment of cotton seedlings reduced the incidence of Xanthomonas axonopodis pv. malvacearum (Xam) causal organism for bacterial blight disease(Griffin et al. 2006). In addition, foliar inoculation of grapevine with conidial suspensions of B. bassiana reduced the prevalence of downy mildew disease caused by Plasmopara viticola (Berk. and Curt.) (Oomycota: Peronosporaceae)(Jaber 2015).

Recently, seed treatment of wheat with Beauveria bassiana (NATURALIS) and Metarhizium brunneum 
(BIPESCO5) reduced crown and root rot (CRR) in wheat (Jaber 2018) and sweet pepper (Jaber \& Alananbeh 2018) a disease caused by Fusarium culmorum. Although not fully elucidated, multiple but not mutually exclusive mechanisms have been proposed (Ownley et al. 2008; Gao et al. 2010; Ownley et al. 2010; Jaber 2018; Jaber \& Ownley 2018). Disease suppression by endophytic entomopathogenic fungi has been described as both direct effects including mycoparasitism, competition and antibiosis, as well as indirect effects such as secondary metabolites, promotion of plant growth and induction of systemic plant resistance as possible mechanisms (Ownley et al. 2010; Jaber 2018; Jaber \& Ownley 2018). Mycoparasitism has been observed for Pythium myriotylum by B. bassiana in vitro (Ownley et al. 2008) as well as by Lecanicillium against Pythium ultimum both in vitro and in planta (Benhamou \& Brodeur 2001). Antibiosis (production of secondary metabolites), another mechanism was demonstrated by Beauveria bassiana (NATURALIS) and Metarhizium brunneum (BIPESCO5) against Fusarium culmorum when these two fungi were co-cultured with the pathogen in dual plate assays(Jaber \& Alananbeh 2018). In this study, competition for the resource was also observed with clear zones of inhibition that occurred at the interface with the pathogenic fungus (Jaber \& Alananbeh 2018).

Entomopathogenic fungi are well-known to produce an array of secondary metabolites of antibacterial, antifungal and insecticidal origin (Gibson et al. 2014) which has been an important mechanism involved in controlling plant pathogenic fungi (Gibson et al. 2014). Another indirect mechanism is the induction of systemic resistance in the plant; a mechanism has been found to be used by B. bassiana against Xanthomonas axonopodis pv. malvacearum in cotton (Ownley et al. 2008) and zucchini yellow mosaic virus in pumpkin (Jaber \& Salem 2014). The above studies indicate that fungal entomopathogens have a great potential to be developed as biopesticides for multi-purpose functionality in integrated pest management programs (Goettel et al., 2008, Vega et al., 2009 and Ownley et al., 2010).

\section{Endophytic insect pathogenic fungi as insect antagonists}

From the endophyte research in the last decades, there is now substantial evidence that entomopathogenic fungi can play multiple roles besides their well-known insect pathogenic activities especially association with the plant as an endophyte (Vega et al. 2009; Vega 2018). Endophytic presence of entomopathogenic fungi provides multiple benefits to the host plant in planta such as insect control, plant disease antagonist, plant growth promotion (Vega et al. 2009). There are a plethora of recent studies on insect control abilities of endophytic entomopathogenic fungi following their colonization in planta through various inoculation methods (Jaber \& Ownley 2018; Vega 2018).

In a recent review, Vega (2018) reported that 39 out of 85 papers $(46 \%)$ examined the effects of endophytism by EPF on 33 insect species from 17 families and 8 orders where negative effects on insect pests were reported in 38 studies. Endophytic colonization of crop plants by $B$. bassiana has been reported to reduce damage caused by stem and corn borers Ostrinia nubilalis and Sesamia calamistis (Lepidoptera: Noctuidae) in maize (Bing \& Lewis 1991; Bing \& Lewis 1992a, b); Chilo partellus (Lepidoptera: Pyralidae) in Sorghum (Reddy et al. 2009); Plutella xylostella (Lepidoptera: Plutellidae) in Brassica napus (Brassicaceae) (Batta 2013); fruitworm Helicoverpa zea Boddie (Lepidoptera: Noctuidae) in tomato (Powell et al. 2009; Qayyum et al. 2015); tomato pinworm Tuta absoluta (Lepidoptera:Gelechiidae) in tomato (Klieber \& Reineke 2016); Sesamia nonagrioides, (Lepidoptera: Noctuidae) in sorghum (Mantzoukas et al. 2015); banana weevil, Cosmopolites sordidus (Coleoptera: Curculionidae) in banana (Akello et al. 2008a); stem weevil Apion corchori Marshall (Coleoptera: Curculionidae) in white jute (Biswas et al. 2013); the whitefly, Bemisia tabaci (Hemiptera: Aleyrodidae) in tomato (Wei et al. 2020); very recently the fall armyworm, Spodoptera frugiperda (J. E. Smith) (Lepidoptera: Noctuidae) in corn (Ramos et al. 2020); the two-spotted spider mite, Tetranychus urticae Koch (Acari: Tetranychidae) in common bean Phaseolus vulgaris L. (Fabaceae) (Dash et al. 2018); the Asian citrus psyllid, Diaphorina citri Kuwayama (Hemiptera: Liviidae) in Citrus limon (Bamisile et al. 2019).

Other than B. bassiana, several species of Metarhizium also exhibited negative effects against insects from different feeding guilds (Bamisile et al. 2020; Canassa et al. 2020; Ment et al. 2020). For example, endophytic strains of Metarhizium robertsii reduced relative growth rate of black cutworm, Agrotis ipsilon (Hufnagel) (Lepidoptera: Noctuidae) in maize (Ahmad et al. 2020); corn stalk borer, Sesamia nonagrioides Lefebre (Lepidoptera: Noctuidae) in sweet sorghum (Mantzoukas et al. 2015). In addition, M. anisopliae was found to effect the performance of the bean stem maggot, Ophiomyia phaseoli Tryon (Diptera: Agromyzidae) in bean Phaseolus vulgaris (Mutune et al. 2016). Endophytic establishment of M. anisopliae has been reported to effect Aphis fabae, Acyrthosiphon pisum (Hemiptera: Aphididae) in faba bean, Vicia faba (Leguminosae) (Akello \& Sikora 2012) and Sesamia nonagrioides Lefebre (Lepidoptera: Noctuidae) in sweet sorghum (Mantzoukas et al. 2015).

Negative effects were also recorded for other entomopathogenic fungal endophytes including the cotton aphid, Aphis gossypii Glover (Hemiptera: Aphididae) in cotton (Gurulingappa et al. 2010); the pea leafminer, Liriomyza huidobrensis Blanchard (Diptera: Agromyzidae) with Fusarium oxysporum, Hypocrea lixii and Gibberella moniliformis in broad bean (Akutse et al. 2013) and onion thrips, Thrips tabaci Lindeman (Thysanoptera: Thripidae) with Clonostachys rosea. 
The mechanism underlying the detrimental effects of EIPF on insect hervibores has not yet fully unraveled (Vidal \& Jaber 2015; Vega 2018). While systemic plant resistance has been described against plant disease antagonism, presumably similar systemic resistance is also elicited by EIPF against insect herbivores (Jaber \& Ownley 2018). So far, a very little number of studies had reported mycosis of insect cadavers when herbivore was encountered endophyte colonized plants. Interestingly, a small number of studies reported mycosis, especially when B. bassiana colonized endophytically in the host plant (Powell et al. 2007; Akello et al. 2008a; Akello et al. 2008b; Powell et al. 2009; Vidal \& Jaber 2015; Klieber \& Reineke 2016); although the mechanism leading to mycosis has not been elucidated. In one of those studies, (Powell et al. 2009) assumed that the insect might have consumed an intact and sufficient amount of hypha to cause the mycosis.

Feeding deterrence or antibiosis due to the production of secondary metabolites by fungal endophytes in the colonized plant has been commonly suggested as the mechanism of negative effects on insect herbivores in host plant-endophyte-insect interactions (e.g. (Akello \& Sikora 2012; Akutse et al. 2013; Golo et al. 2014; Muvea et al. 2014; Mantzoukas et al. 2015; Lefort et al. 2016; Dash et al. 2018; Jaber \& Ownley 2018). For example, $B$. bassiana is known to produce numerous secondary metabolites including beauvericin, bassianolides, bassianolone, oosporein, etc. which have been found to have antifungal, antibacterial and insecticidal properties (Ownley et al. 2010; Gibson et al. 2014). Similarly, Metarhizium spp. also produce a variety of secondary metabolites, including destruxins, serinocyclins, cytochalasins etc. (Krasnoff et al. 2007).

\section{Endophytic entomopathogenic fungi as biocontrol agents}

There is now substantial evidence that entomopathogenic fungi can colonize plants following various inoculation techniques (Bamisile et al. 2018) and successful colonization of them provides host plant multiple benefits (Vega et al. 2009; Vega 2018) even they can promote plant growth as well as dual biological control of insect pests and plant pathogenic bacteria, fungi and nematodes (Kabaluk \& Ericsson 2007; Goettel et al. 2008; Kim et al. 2008; Ownley et al. 2010; García et al. 2011; Sasan \& Bidochka 2012; Liao et al. 2014; Bogner et al. 2016; Zhou et al. 2016). Previous studies have reported that in planta presence of endophytic fungi $B$. bassiana can provide longer protection in plants; for example, three months in jute (Biswas et al. 2012) and even upto nine months in radiata pine following endohytic colonization (Brownbridge et al. 2012). Use of endophytic fungal entomopathogen can overcome several inherent problems reported while using EPF as inundative approach (Vega 2018). For example, seed treatment with fungal endophyte have been found to systemically colonize the host plant as they have been recovered from root, stem and even leaves indicating their potential as protecting the whole plant upon a single application as seed treatment (Jaber \& Enkerli 2016; Dash et al. 2018). This suggests that endophyte can offer protection against soil dwelling as well as cryptic pests (e.g. internal borers) which would otherwise be difficult to control by traditional control approaches (Jaronski 2010).

Recently, endophytic strains of entomopathogenic fungi have been reported to be compatible with other biocontrol agents such as predators (Canassa et al. 2019) and parasitoids (Akutse et al. 2014; Gathage et al. 2016; Jaber \& Araj 2018). For example, (Akutse et al. 2014) did not find significant differences in parasitism rate of two parasitoids of the pea leafminer Diglyphus isaea Walker (Hymenoptera: Eulophidae) and Phaedrotoma scabriventris Nixon (Hymenoptera: Braconidae) when parasitized on $2^{\text {nd }}$ and $3^{\text {rd }}$ instar larvae of the pea leaf miner Liriomyza huidobrensis Blanchard (Diptera: Agromyzidae) on broad bean plants colonized by several fungal isolates of B. bassiana and H. lixii. In another study, (Jaber \& Araj 2018) also observed no difference in the development time and adult longevity of Aphidius colemani, a parasitoid of green peach aphid, Myzus persicae in sweet pepper plants colonized by B. bassiana and M brunneum.

In a recent study, (Canassa et al. 2019) inoculated two isolates of Metarhizium robertsii (ESALQ 1622) and Beauveria bassiana (ESALQ 3375) in strawberry through seed treatment to study the effect of endophytism against spider mite, Tetranychus urticae and behavioral responses and predation rates of the predatory mite Phytoseiulus persimilis. The authors reported significant reduction in the populations of Tetranychus urticae whereas the predatory mite $P$. persimilis showed no difference in predation rate when $T$. urticae were provided from endophyte colonized or endophyte free strawberry plants (Canassa et al. 2019). The same author in their recent field study with same isolates demonstrated that no negative effect was reported on numbers of naturally occurring predatory mites in strawberry field when plant root was inoculated with endophytic entomopathogenic fungi (Canassa et al. 2020). All these findings therefore indicate that entomopathogenic fungi as endophyte can be successfully used in IPM program as biocontrol agent.

\section{Conclusions and future perspectives}

Due to increased environmental concerns about the consequences of synthetic chemical pesticides, efforts are being concentrated on developing eco-friendly pest management techniques and biological control is considered as sustainable pest management option in IPM. Recent discovery of endophytic properties of EPF provides great opportunities to overcome many limitations faced during their innundative use and offer long term protection of host plant from biotic and abiotic stresses. 
To date, most of the endophyte research have been conducted in the laboratory or greenhouses, very few have been examined in field condition (but see (Cherry et al. 2004; Quesada-Moraga et al. 2009; Castillo Lopez et al. 2014; Mantzoukas et al. 2015; Gathage et al. 2016; Canassa et al. 2020). For example, Parsa et al. (2018) demonstrated that endophytic colonization of fungal isolates were significantly reduced when natural field soil was used instead of sterile soil with the same isolate. This study indicates that the effectiveness of the promising technology needs to be proven in the field condition before it can be recommended for commercial use for economic benefits to the growers.

Although there are numerous studies on endophytic entomopathogenic fungi, very few species (Beauveria, Metarhizium. Lecanicillium) have been studied to date. Therefore research should be extended for other unexplored potential insect pathogenic fungi for their ability to interact with plants as endophyte. A deeper understanding about the association and persistence of entomopathogenic fungi in the host plant is necessary before they can be recommended for incorporating into IPM program. A better understanding on the cost to host fitness while establishing EPF is also required.

A deeper understanding of host-endophyte relationships at the molecular level can help to explore the mechanism of endophytism by EPF. The evaluation of various inoculation methods for extended colonization is also necessary for effective management strategy. Moreover, it is clear that fungi produce several secondary metabolites during their endophytic presence in the host plant; possibility of producing toxic metabolite and their inclusion in the human food chain also need to be carefully examined.

\section{References}

Ahmad, I., Jiménez-Gasco, M.d.M., Luthe, D.S., Shakeel, S.N. \& Barbercheck, M.E. (2020). Endophytic Metarhizium robertsii promotes maize growth, suppresses insect growth, and alters plant defense gene expression. Biological Control, 144, 104167.

Akello, J., Dubois, T., Coyne, D. \& Kyamanywa, S. (2008a). Effect of endophytic Beauveria bassiana on populations of the banana weevil, Cosmopolites sordidus, and their damage in tissue-cultured banana plants. Entomologia Experimentalis Et Applicata, 129, 157-165.

Akello, J., Dubois, T., Coyne, D. \& Kyamanywa, S. (2008b). Endophytic Beauveria bassiana in banana (Musa spp.) reduces banana weevil (Cosmopolites sordidus) fitness and damage. Crop Protection, 27, 1437-1441.

Akello, J. \& Sikora, R. (2012). Systemic acropedal influence of endophyte seed treatment on Acyrthosiphon pisum and Aphis fabae offspring development and reproductive fitness. Biological Control, 61, 215-221.

Akutse, K.S., Fiaboe, K.K.M., Van den Berg, J., Ekesi, S. \& Maniania, N.K. (2014). Effects of Endophyte Colonization of Vicia faba (Fabaceae) Plants on the Life-History of Leafminer Parasitoids Phaedrotoma scabriventris (Hymenoptera: Braconidae) and Diglyphus isaea (Hymenoptera: Eulophidae). Plos One, 9.

Akutse, K.S., Maniania, N.K., Fiaboe, K.K.M., Van den Berg, J. \& Ekesi, S. (2013). Endophytic colonization of Vicia faba and Phaseolus vulgaris (Fabaceae) by fungal pathogens and their effects on the life-history parameters of Liriomyza huidobrensis (Diptera: Agromyzidae). Fungal Ecology, 6, 293-301.

Arnold, A.E. \& Lewis, L.C. (2005). Ecology and evolution of fungal endophytes, and their roles against insects. Insect-Fungal Associations: Ecology and Evolution. Oxford University Press, New York, 74-96.

Bamisile, B.S., Dash, C.K., Akutse, K.S., Keppanan, R., Afolabi, O.G., Hussain, M. et al. (2018). Prospects of endophytic fungal entomopathogens as biocontrol and plant growth promoting agents: An insight on how artificial inoculation methods affect endophytic colonization of host plants. Microbiological Research, 217, 34-50.

Bamisile, B.S., Dash, C.K., Akutse, K.S., Qasim, M., Ramos Aguila, L.C., Wang, F. et al. (2019). Endophytic Beauveria bassiana in foliar-treated Citrus limon plants acting as a growth suppressor to three successive generations of Diaphorina citri Kuwayama (Hemiptera: Liviidae). Insects, 10.

Bamisile, B.S., Senyo Akutse, K., Dash, C.K., Qasim, M., Ramos Aguila, L.C., Ashraf, H.J. et al. (2020). Effects of seedling age on colonization patterns of Citrus limon plants by endophytic Beauveria bassiana and Metarhizium anisopliae and their influence on seedlings growth. Journal of Fungi, 6, 29.

Barelli, L., Moonjely, S., Behie, S.W. \& Bidochka, M.J. (2016). Fungi with multifunctional lifestyles: endophytic insect pathogenic fungi. Plant Molecular Biology, 90, 657-664.

Barra-Bucarei, L., France Iglesias, A., Gerding González, M., Silva Aguayo, G., Carrasco-Fernández, J., Castro, J.F. et al. (2020). Antifungal Activity of Beauveria bassiana Endophyte against Botrytis cinerea in Two Solanaceae Crops. Microorganisms, 8, 65.

Batta, Y.A. (2013). Efficacy of endophytic and applied Metarhizium anisopliae (Metch.) Sorokin (Ascomycota: Hypocreales) against larvae of Plutella xylostella L. (Yponomeutidae: Lepidoptera) infesting Brassica napus plants. Crop Protection, 44, 128-134.

Behie, S.W., Moreira, C.C., Sementchoukova, I., Barelli, L., Zelisko, P.M. \& Bidochka, M.J. (2017). Carbon translocation from a plant to an insect-pathogenic endophytic fungus. Nature Communication, 8, 1424514245 . 
Behie, S.W., Zelisko, P.M. \& Bidochka, M.J. (2012). Endophytic Insect-Parasitic Fungi Translocate Nitrogen Directly from Insects to Plants. Science, 336, 1576-1577.

Benhamou, N. \& Brodeur, J. (2001). Pre-inoculation of Ri T-DNA transformed cucumber roots with the mycoparasite, Verticillium lecanii, induces host defense reactions against Pythium ultimum infection. Physiological and Molecular Plant Pathology, 58, 133-146.

Berg, G. (2009). Plant-microbe interactions promoting plant growth and health: perspectives for controlled use of microorganisms in agriculture. Applied Microbiology and Biotechnology, 84, 11-18.

Bing, L.A. \& Lewis, L.C. (1991). Suppression of Ostrinia nubilalis (Hübner) (Lepidoptera: Pyralidae) by endophytic Beauveria bassiana (Balsamo) Vuillemin. Environmental Entomology, 20, 1207-1211.

Bing, L.A. \& Lewis, L.C. (1992a). Endophytic Beauveria bassiana (balsamo) vuillemin in corn: The influence of the plant growth stage and Ostrinia nubilalis (hübner). Biocontrol Science and Technology, 2, 39-47.

Bing, L.A. \& Lewis, L.C. (1992b). Temporal relationships between Zea mays, Ostrinia nubilalis (Lep.: Pyralidae) and endophytic Beauveria bassiana. Entomophaga, 37, 525-536.

Biswas, C., Dey, P., Satpathy, S. \& Satya, P. (2012). Establishment of the fungal entomopathogen Beauveria bassiana as a season long endophyte in jute (Corchorus olitorius) and its rapid detection using SCAR marker. Biocontrol, 57, 565-571.

Biswas, C., Dey, P., Satpathy, S., Satya, P. \& Mahapatra, B.S. (2013). Endophytic colonization of white jute (Corchorus capsularis) plants by different Beauveria bassiana strains for managing stem weevil (Apion corchori). Phytoparasitica, 41, 17-21.

Bogner, C.W., Kariuki, G.M., Elashry, A., Sichtermann, G., Buch, A.K., Mishra, B. et al. (2016). Fungal root endophytes of tomato from Kenya and their nematode biocontrol potential. Mycological Progress, 15.

Brownbridge, M., Reay, S.D., Nelson, T.L. \& Glare, T.R. (2012). Persistence of Beauveria bassiana (Ascomycota: Hypocreales) as an endophyte following inoculation of radiata pine seed and seedlings. Biological Control, 61, 194-200.

Canassa, F., Esteca, F.C.N., Moral, R.A., Meyling, N.V., Klingen, I. \& Delalibera, I. (2020). Root inoculation of strawberry with the entomopathogenic fungi Metarhizium robertsii and Beauveria bassiana reduces incidence of the two-spotted spider mite and selected insect pests and plant diseases in the field. Journal of Pest Science, 93, 261-274.

Canassa, F., Tall, S., Moral, R.A., Lara, I.A.R.d., Delalibera, I. \& Meyling, N.V. (2019). Effects of bean seed treatment by the entomopathogenic fungi Metarhizium robertsii and Beauveria bassiana on plant growth, spider mite populations and behavior of predatory mites. Biological Control, 132, 199-208.

Carroll, G. (1988). Fungal Endophytes in Stems and Leaves: From Latent Pathogen to Mutualistic Symbiont. Ecology, 69, 2-9.

Castillo Lopez, D., Zhu-Salzman, K., Ek-Ramos, M.J. \& Sword, G.A. (2014). The entomopathogenic fungal endophytes Purpureocillium lilacinum (formerly Paecilomyces lilacinus) and Beauveria bassiana negatively affect cotton aphid reproduction under both greenhouse and field conditions. PLoS One, 9, e103891.

Cherry, A., Banito, A., Djegui, D. \& Lomer, C. (2004). Suppression of the stem-borer Sesamia calamistis (Lepidoptera; Noctuidae) in maize following seed dressing, topical application and stem injection with African isolates of Beauveria bassiana. International Journal of Pest Management, 50, 67-73.

Culliney, T.W. (2014). Crop Losses to Arthropods. In: Integrated Pest Management: Pesticide Problems, Vol.3 (eds. Pimentel, D \& Peshin, R). Springer Netherlands Dordrecht, pp. 201-225.

Dash, C.K., Bamisile, B.S., Keppanan, R., Qasim, M., Lin, Y., Islam, S.U. et al. (2018). Endophytic entomopathogenic fungi enhance the growth of Phaseolus vulgaris L. (Fabaceae) and negatively affect the development and reproduction of Tetranychus urticae Koch (Acari: Tetranychidae). Microbial Pathogenesis, $125,385-392$.

El-Deeb, H.M., Lashin, S.M. \& Arab, Y.A.-S. (2012). Reaction of some tomato cultivars to tomato leaf curl virus and evaluation of the endophytic colonisation with Beauveria bassiana on the disease incidence and its vector, Bemisia tabaci. Archives of Phytopathology and Plant Protection, 45, 1538-1545.

Elena, G.J., Beatriz, P.J., Alejandro, P. \& Lecuona, R. (2011). Metarhizium anisopliae (Metschnikoff) Sorokin promotes growth and has endophytic activity in tomato plants. Advances in Biological Research, 5, $22-27$.

Gao, F.-k., Dai, C.-c. \& Liu, X.-z. (2010). Mechanisms of fungal endophytes in plant protection against pathogens. African Journal of Microbiology Research, 4, 1346-1351.

García, J., Elena, Posadas, J., Beatriz, P., Alejandro, L. \& Roberto, E. (2011). Metarhizium anisopliae (Metschnikoff) Sorokin Promotes Growth and Has Endophytic Activity in Tomato Plants. Advances in Biological Research, 5, 22-27.

Gathage, J.W., Lagat, Z.O., Fiaboe, K.K.M., Akutse, K.S., Ekesi, S. \& Maniania, N.K. (2016). Prospects of fungal endophytes in the control of Liriomyza leafminer flies in common bean Phaseolus vulgaris under field conditions. BioControl, 61, 741-753.

Gibson, D.M., Donzelli, B.G., Krasnoff, S.B. \& Keyhani, N.O. (2014). Discovering the secondary metabolite 
potential encoded within entomopathogenic fungi. Natural Product Reports, 31, 1287-1305.

Goettel, M.S., Koike, M., Kim, J.J., Aiuchi, D., Shinya, R. \& Brodeur, J. (2008). Potential of Lecanicillium spp. for management of insects, nematodes and plant diseases. Journal of Invertebrate Pathology, 98, 256-261.

Golo, P.S., Gardner, D.R., Grilley, M.M., Takemoto, J.Y., Krasnoff, S.B., Pires, M.S. et al. (2014). Production of destruxins from Metarhizium spp. fungi in artificial medium and in endophytically colonized cowpea plants. Plos One, 9.

Griffin, M.R., Ownley, B.H., Klingeman, W.E. \& Pereira, R.M. (2006). Evidence of induced systemic resistance with Beauveria bassiana against Xanthomonas in cotton. Phytopathology, 96, S42-S42.

Gurulingappa, P., Sword, G.A., Murdoch, G. \& McGee, P.A. (2010). Colonization of crop plants by fungal entomopathogens and their effects on two insect pests when in planta. Biological Control, 55, 34-41.

Hu, G. \& St. Leger, R.J. (2002). Field studies using a recombinant mycoinsecticide (Metarhizium anisopliae) reveal that it is rhizosphere competent. Applied and Environmental Microbiology, 68, 6383-6387.

Jaber, L.R. (2015). Grapevine leaf tissue colonization by the fungal entomopathogen Beauveria bassiana s.1. and its effect against downy mildew. Biocontrol, 60, 103-112.

Jaber, L.R. (2018). Seed inoculation with endophytic fungal entomopathogens promotes plant growth and reduces crown and root rot (CRR) caused by Fusarium culmorum in wheat. Planta, 248, 1525-1535.

Jaber, L.R. \& Alananbeh, K.M. (2018). Fungal entomopathogens as endophytes reduce several species of Fusarium causing crown and root rot in sweet pepper (Capsicum annuum L.). Biological Control, 126, 117126.

Jaber, L.R. \& Araj, S.-E. (2018). Interactions among endophytic fungal entomopathogens (Ascomycota: Hypocreales), the green peach aphid Myzus persicae Sulzer (Homoptera: Aphididae), and the aphid endoparasitoid Aphidius colemani Viereck (Hymenoptera: Braconidae). Biological Control, 116, 53-61.

Jaber, L.R. \& Enkerli, J. (2016). Effect of seed treatment duration on growth and colonization of Vicia faba by endophytic Beauveria bassiana and Metarhizium brunneum. Biological Control, 103, 187-195.

Jaber, L.R. \& Enkerli, J. (2017). Fungal entomopathogens as endophytes: can they promote plant growth? Biocontrol Science and Technology, 27, 28-41.

Jaber, L.R. \& Ownley, B.H. (2018). Can we use entomopathogenic fungi as endophytes for dual biological control of insect pests and plant pathogens? Biological Control, 116, 36-45.

Jaber, L.R. \& Salem, N.M. (2014). Endophytic colonisation of squash by the fungal entomopathogen Beauveria bassiana (Ascomycota: Hypocreales) for managing Zucchini yellow mosaic virusin cucurbits. Biocontrol Science and Technology, 24, 1096-1109.

Jaronski, S.T. (2010). Ecological factors in the inundative use of fungal entomopathogens. Biocontrol, 55, 159185.

Jirakkakul, J., Cheevadhanarak, S., Punya, J., Chutrakul, C., Senachak, J., Buajarern, T. et al. (2014). Tenellin acts as an iron chelator to prevent iron-generated reactive oxygen species toxicity in the entomopathogenic fungus Beauveria bassiana. FEMS Microbiology Letters, 362, 1-8.

Jones, K. (1994). Aspects of the biology and biological control of the European corn borer in North Carolina [Doctoral dissertation]. Raleigh: North Carolina State University.

Kabaluk, J.T. \& Ericsson, J.D. (2007). Metarhizium anisopliae seed treatment increases yield of field corn when applied for wireworm control. Agron. J., 99, 1377-1381.

Khachatourians, G.G. \& Qazi, S.S. (2008). Entomopathogenic Fungi: Biochemistry and Molecular Biology. In: Human and Animal Relationships (eds. Brakhage, AA \& Zipfel, PF). Springer Berlin Heidelberg Berlin, Heidelberg, pp. 33-61.

Khan, A.L., Hamayun, M., Khan, S.A., Kang, S.-M., Shinwari, Z.K., Kamran, M. et al. (2012). Pure culture of Metarhizium anisopliae LHL07 reprograms soybean to higher growth and mitigates salt stress. World Journal of Microbiology \& Biotechnology, 28, 1483-1494.

Kim, J.J., Goettel, M.S. \& Gillespie, D.R. (2008). Evaluation of Lecanicillium longisporum, Vertalec (R) for simultaneous suppression of cotton aphid, Aphis gossypii, and, cucumber powdery mildew, Sphaerotheca fuliginea, on potted cucumbers. Biological Control, 45, 404-409.

Klieber, J. \& Reineke, A. (2016). The entomopathogen Beauveria bassiana has epiphytic and endophytic activity against the tomato leaf miner Tuta absoluta. Journal of Applied Entomology, 140, 580-589.

Krasnoff, S.B., Keresztes, I., Gillilan, R.E., Szebenyi, D.M.E., Donzelli, B.G.G., Churchill, A.C.L. et al. (2007). Serinocyclins A and B, Cyclic Heptapeptides from Metarhizium anisopliae. Journal of Natural Products, 70, 1919-1924.

Lacey, L.A., Grzywacz, D., Shapiro-Ilan, D.I., Frutos, R., Brownbridge, M. \& Goettel, M.S. (2015). Insect pathogens as biological control agents: Back to the future. Journal of Invertebrate Pathology, 132, 1-41.

Le Cocq, K., Gurr, S.J., Hirsch, P.R. \& Mauchline, T.H. (2017). Exploitation of endophytes for sustainable agricultural intensification. Molecular Plant Pathology, 18, 469-473.

Lefort, M.C., McKinnon, A.C., Nelson, T.L. \& Glare, T.R. (2016). Natural occurrence of the entomopathogenic 
fungi Beauveria bassiana as a vertically transmitted endophyte of Pinus radiata and its effect on above- and below-ground insect pests. New Zealand Plant Protection, 69, 68-77.

Liao, X., Lovett, B., Fang, W. \& St Leger, R.J. (2017). Metarhizium robertsii produces indole-3-acetic acid, which promotes root growth in Arabidopsis and enhances virulence to insects. Microbiology-Sgm, 163, 980-991.

Liao, X.G., O'Brien, T.R., Fang, W.G. \& St Leger, R.J. (2014). The plant beneficial effects of Metarhizium species correlate with their association with roots. Applied Microbiology and Biotechnology, 98, 7089-7096.

Lopez, D.C. \& Sword, G.A. (2015). The endophytic fungal entomopathogens Beauveria bassiana and Purpureocillium lilacinum enhance the growth of cultivated cotton (Gossypium hirsutum) and negatively affect survival of the cotton bollworm (Helicoverpa zea). Biological Control, 89, 53-60.

Mantzoukas, S., Chondrogiannis, C. \& Grammatikopoulos, G. (2015). Effects of three endophytic entomopathogens on sweet sorghum and on the larvae of the stalk borer Sesamia nonagrioides. Entomologia Experimentalis et Applicata, 154, 78-87.

Ment, D., Raman, S., Gal, S., Ezra, D. \& Palevsky, E. (2020). Interactions of Metarhizium brunneum-7 with phytophagous mites following different application strategies. Insects, 11, 330.

Mutune, B., Ekesi, S., Niassy, S., Matiru, V., Bii, C. \& Maniania, N.K. (2016). Fungal endophytes as promising tools for the management of bean stem maggot Ophiomyia phaseoli on beans Phaseolus vulgaris. Journal of Pest Science, 89, 993-1001.

Muvea, A.M., Meyhoefer, R., Subramanian, S., Poehling, H.-M., Ekesi, S. \& Maniania, N.K. (2014). Colonization of onions by endophytic fungi and their impacts on the biology of Thrips tabaci. Plos One, 9.

Ownley, B.H., Griffin, M.R., Klingeman, W.E., Gwinn, K.D., Moulton, J.K. \& Pereira, R.M. (2008). Beauveria bassiana: endophytic colonization and plant disease control. Journal of Invertebrate Pathology, 98, 267-270.

Ownley, B.H., Gwinn, K.D. \& Vega, F.E. (2010). Endophytic fungal entomopathogens with activity against plant pathogens: ecology and evolution. Biocontrol, 55, 113-128.

Ownley, B.H., Pereira, R.M., Klingeman, W.E., Quigley, N.B., Leckie, B.M., Lartey, R.T. et al. (2004). Beauveria bassiana, a dual purpose biocontrol organism, with activity against insect pests and plant pathogens. OAI.

Parsa, S., Ortiz, V., Gómez-Jiménez, M.I., Kramer, M. \& Vega, F.E. (2018). Root environment is a key determinant of fungal entomopathogen endophytism following seed treatment in the common bean, Phaseolus vulgaris. Biological Control, 116, 74-81.

Pava-Ripoll, M., Angelini, C., Fang, W., Wang, S., Posada, F.J. \& St Leger, R. (2011). The rhizosphere-competent entomopathogen Metarhizium anisopliae expresses a specific subset of genes in plant root exudate. Microbiology, 157, 47-55.

Powell, W.A., Klingeman, W.E., Ownley, B.H. \& Gwinn, K.D. (2009). Evidence of endophytic Beauveria bassiana in seed-treated tomato plants acting as a systemic entomopathogen to larval Helicoverpa zea (Lepidoptera: Noctuidae). Journal of Entomological Science, 44, 391-396.

Powell, W.A., Klingeman, W.E., Ownley, B.H., Gwinn, K.D., Dee, M. \& Flanagan, P.C. (2007). Endophytic Beauveria bassiana in tomatoes yields mycosis in tomato fruitworm larvae. Hortscience, 42, 933-933.

Qayyum, M.A., Wakil, W., Arif, M.J., Sahi, S.T. \& Dunlap, C.A. (2015). Infection of Helicoverpa armigera by endophytic Beauveria bassiana colonizing tomato plants. Biological Control, 90, 200-207.

Quesada-Moraga, E., Munoz-Ledesma, F.J. \& Santiago-Alvarez, C. (2009). Systemic Protection of Papaver somniferum L. against Iraella luteipes (Hymenoptera: Cynipidae) by an Endophytic Strain of Beauveria bassiana (Ascomycota: Hypocreales). Environmental Entomology, 38, 723-730.

Ramos, Y., Taibo, A.D., Jiménez, J.A. \& Portal, O. (2020). Endophytic establishment of Beauveria bassiana and Metarhizium anisopliae in maize plants and its effect against Spodoptera frugiperda (J. E. Smith) (Lepidoptera: Noctuidae) larvae. Egyptian Journal of Biological Pest Control, 30, 20.

Reay, S.D., Brownbridge, M., Gicquel, B., Cummings, N.J. \& Nelson, T.L. (2010). Isolation and characterization of endophytic Beauveria spp. (Ascomycota: Hypocreales) from Pinus radiata in New Zealand forests. Biological Control, 54, 52-60.

Reddy, G.V., Tangtrakulwanich, K., Wu, S., Miller, J.H., Ophus, V.L., Prewett, J. et al. (2014). Evaluation of the effectiveness of entomopathogens for the management of wireworms (Coleoptera: Elateridae) on spring wheat. Journal of Invertebrate Pathology, 120, 43-49.

Reddy, N.P., Khan, A.R.A., Devi, U.K., Sharma, H.C. \& Reineke, A. (2009). Treatment of millet crop plant (Sorghum bicolor) with the entomopathogenic fungus (Beauveria bassiana) to combat infestation by the stem borer, Chilo partellus Swinhoe (Lepidoptera: Pyralidae). Journal of Asia-Pacific Entomology, 12, 221-226.

Sasan, R.K. \& Bidochka, M.J. (2012). The insect-pathogenic fungus Metarhizium robertsii (Clavicipitaceae) is also an endophyte that stimulates plant root development. American journal of botany, 99, 101-107.

Sasan, R.K. \& Bidochka, M.J. (2013). Antagonism of the endophytic insect pathogenic fungus Metarhizium robertsii against the bean plant pathogen Fusarium solani f. sp phaseoli. Canadian Journal of Plant Pathology, 35, 288-293.

Skinner, M., Parker, B.L. \& Kim, J.S. (2014). Role of Entomopathogenic Fungi in Integrated Pest Management. 
St. Leger, R.J. (2008). Studies on adaptations of Metarhizium anisopliae to life in the soil. Journal of Invertebrate Pathology, 98, 271-276.

van Lenteren, J.C., Bolckmans, K., Köhl, J., Ravensberg, W.J. \& Urbaneja, A. (2018). Biological control using invertebrates and microorganisms: plenty of new opportunities. BioControl, 63, 39-59.

Vega, F.E. (2018). The use of fungal entomopathogens as endophytes in biological control: a review. Mycologia, 110, 4-30.

Vega, F.E., Goettel, M.S., Blackwell, M., Chandler, D., Jackson, M.A., Keller, S. et al. (2009). Fungal entomopathogens: new insights on their ecology. Fungal Ecology, 2, 149-159.

Vega, F.E., Posada, F., Aime, M.C., Pava-Ripoll, M., Infante, F. \& Rehner, S.A. (2008). Entomopathogenic fungal endophytes. Biological Control, 46, 72-82.

Vidal, S. \& Jaber, L.R. (2015). Entomopathogenic fungi as endophytes: Plant-endophyte-herbivore interactions and prospects for use in biological control. Current Science, 109, 46-54.

Wei, Q.-Y., Li, Y.-Y., Xu, C., Wu, Y.-X., Zhang, Y.-R. \& Liu, H. (2020). Endophytic colonization by Beauveria bassiana increases the resistance of tomatoes against Bemisia tabaci. Arthropod-Plant Interactions, 14, 289 300.

Zhou, W., Wheeler, T.A., Starr, J.L., Valencia, C.U. \& Sword, G.A. (2016). A fungal endophyte defensive symbiosis affects plant-nematode interactions in cotton. Plant and Soil, 1-16. 